\title{
APPLICATION OF QUALITY BY DESIGN APPROACH FOR THE OPTIMIZATION OF ORODISPERSIBLE FILM FORMULATION
}

\author{
ASHUTOSH GUPTA, JATIN KUMAR, SURAJPAL VERMA*, HARMANPREET SINGH* \\ Department of Pharmaceutics, School of Pharmaceutical Sciences, Lovely Professional University, Phagwara, Punjab, India. \\ Email: surajpal.15834@lpu.co.in
}

Received: 10 February 2018, Revised and Accepted: 20 February 2018

\section{ABSTRACT}

Objective: The present study was done to understand the effect of formulation variables on the quality of orodispersible films using quality by design (QbD) approach as mentioned in ICH Q8 $\left(\mathrm{R}^{2}\right)$ guideline.

Methods: A definitive screening design of experiments (DoE) was used to identify and classify the critical formulation variables affecting critical quality attributes (CQA) using $2 \times 2$ factorial design. Based on prescreening study, the critical formulation variables, i.e. concentration of film-forming polymer and plasticizers (propylene glycol and polyethylene glycol 400 [PEG 400]) were kept in the range of $1.5-2.5 \% \mathrm{w} / \mathrm{w}$ and $0.5-1 \% \mathrm{v} / \mathrm{v}$, respectively. A total of eight laboratory-scale formulations were prepared which were provided by DoE using solvent casting method. These batches were evaluated for CQA's, i.e. mechanical properties such as folding endurance (FD) and disintegration time (DT). Data were analyzed for elucidating interactions between two variables and for providing a predictive model for the process. Finally, the drug was incorporated into optimized batches, and these were evaluated for in vitro dissolution study in simulated saliva (pH 6.8) as well as their mechanical properties.

Results: The results suggested that the concentration of film-forming polymer and plasticizer was critical to manufacture orodispersible film with desired CQA, i.e. mechanical property (FD [ $>150$ folds]) and DT ( $<60$ s). The percent drug release, FD, and DT of optimized Formulation I (hydroxypropyl methylcellulose [HPMC] E5 (2\%) and propylene glycol [0.15 mL]) were found to be $82.13 \% \pm 0.260$ (in $15 \mathrm{~min}$ ), $164 \pm 2$, and $49 \pm 1.5 \mathrm{~s}$, respectively, and for optimized Formulation II (HPMC E5 [2\%] and PEG 400 [0.15 mL]) was found to be $64.26 \% \pm 2.026$ (in $15 \mathrm{~min}$ ) and $218 \pm 6$ and $55 \pm 4$ s, respectively.

Conclusion: From the results, it has been found that the percentage drug release of naratriptan hydrochloride containing propylene glycol as a plasticizer was greater than the formulation containing PEG 400 as plasticizer. From this, we concluded that QbD is very much useful approach to get an optimized formulation in an economic and faster way in comparison to traditional method (hit and trail methods). The futuristic application of the film will involve the management of an acute migraine.

Keywords: Quality by design, Design of experiments, Critical quality attributes, Folding endurance, Naratriptan hydrochloride, Migraine.

(c) 2018 The Authors. Published by Innovare Academic Sciences Pvt Ltd. This is an open access article under the CC BY license (http://creativecommons. org/licenses/by/4. 0/) DOI: http://dx.doi.org/10.22159/ajpcr.2018.v11s2.28508

\section{INTRODUCTION}

In the past few years, the pharmaceutical company or researchers mainly focus on those drug delivery systems, which provide faster onset of action of drug, enhanced bioavailability, and high patient compliance [1]. Nowadays, the best route for the administration of drug is oral as compared to other drug delivery route [2]. From all the dosage forms available in the market, there is a one solid dosage form, which has a high potential, and it also, fulfills these requirements are orodispersible films [3]. According to the Borges et al., the patients who are suffering from dysphagia, orodispersible film approach is very beneficial and useful for the delivery of the drug. Orodispersible film offers some features such as portability, stability, and flexibility, which confer superiority over the orodispersible capsules, and tablets [4]. An orodispersible films are very thin with the shape of postage stamp containing active pharmaceutical ingredient, polymers, and with or without plasticizers. An orodispersible film when placed onto the mucosal surface instantly gets wetted with saliva. After wetting it rapidly disintegrate and release its medicament [5]. The drawbacks of orodispersible films include moisture sensitivity, extreme temperature, high loading dose problem, and requirement of costly packaging [6].

\footnotetext{
Advantages of orodispersible film

- Quick onset of action

- Enhance bioavailability

- Avoid first pass metabolism

- Ease of transportation and handling
}

- Taste masking

- No such apparatus is required for the preparation

- Site-specific and local action [7].

The pharmaceutical quality by design (QbD) is a systemic approach to development that begins with the predefined objectives and emphasizes product and process understanding and process control, based on sound science and quality risk management [8].

Critical process parameter (CPP) whose variability has an impact on a critical quality attributes (CQA) and therefore should be monitored or controlled to ensure the process produces the desired quality.

CQA are chemical, physical, biological, and microbiological attributes that can be defined, measured, and continually monitored to ensure final product outputs remain within acceptable quality limits.

Acute migraine is a disabling disorder characterized by moderate to severe throbbing, pulsating pain often associated with photophobia, phonophobia, nausea, and vomiting. It worsens with day to day activity of patient $[9,10]$. An untreated migraine attack can past for $4-72 \mathrm{~h}[11,12]$. Sexual dimorphism is reported in migraine, i.e. prevalence ratio among men and women is $3: 7[13,14]$.

There are two approaches through which we can manage migraine, i.e. symptomatic therapy which further divided into two, i.e. use of nonspecific drugs and specific drugs (ergot alkaloids and triptans), depends 
on the efficacy of migraine attack. The second approach is preventative therapy, in which doctor gives the suggestion about daily life routine to the patients [15]. There are majorly conventional tablets available in the market, which is used for management of an acute migraine. Our film has more advantage over that as discussed above.

Naratriptan is a serotonin $5-\mathrm{HT}_{1 \mathrm{~B} / 1 \mathrm{D}}$ receptor agonist and is used for the treatment of acute migraine. Activation of $5-\mathrm{HT}_{1 \mathrm{~B}}$ receptor, which is present on the vascular smooth muscles, causes vasoconstriction of smooth muscles [16]. Activation of $5-\mathrm{HT}_{1 \mathrm{D}}$ which is located on the sensory trigeminal terminals inhibits the release of sensory and vasoactive neuropeptides and vasodilator transmitters $[17,18]$.

\section{MATERIALS AND METHODS}

Naratriptan hydrochloride was obtained as gift samples from Apotex Pharmachem Pvt., Ltd., India. Hydroxypropyl methylcellulose (HPMC) E5, propylene glycol, and polyethylene glycol 400 (PEG 400) were purchased from Loba Chemie. All other chemicals and reagents used were of analytical grade.

\section{Preparation of orodispersible placebo film}

Solvent casting method was used for the preparation of film. In this method initially, all the polymers are dissolved in the suitable solvent, and the drug and other additives are mixed in the other beaker containing suitable solvent. After that mix both the solution and stir it for some time. Then, the solution is subjected to the sonicator to eradicate the air bubble. Finally, that solution is transferred into Teflon or glass Petri plate and then placed in an oven for overnight at $50-60^{\circ} \mathrm{C}$ for drying. Peel out the film and kept in the desiccator till further use (Fig. 1) [19]. The film was cut in a piece of $3 \times 1 \mathrm{~cm}^{2}$ for further evaluation with the help of surgical blade.

\section{QbD approach to develop orodispersible placebo film}

A definitive screening design of experiments (DoE) was used to identify and classify the CPP affecting CQA using $2 \times 2$ factorial design. In this research study, we have considered CPP is concentration of HPMC E5, propylene glycol, and PEG 400. From the literature, we get to know about the concentration of above through which, good film was obtained with desired outcomes. If we increase the concentration of polymer, then there would be problem takes place during pouring, and resulting film is too thick. If we decrease the concentration, film becomes too thin, and it does not give desired outcomes. The main purpose of focusing disintegration time (DT) and folding endurance (FD) as CQA because if the DT is more than $60 \mathrm{~s}$, then there may be chances that patient may split it. This is reason we get eight batches after applying DoE (Figs. 2 and 3).

\section{Evaluation of orodispersible placebo film}

FD

It is the number of times a film could be folded manually at the same place without getting crack on it. It was checked by folding each film repeatedly at the same place until it breaks or folding it for 150 times whichever is less [20].

In vitro $D T$

It tells about the disintegration and dissolution features of the film. Films from each batch of dimensions $3 \mathrm{~cm} \times 1 \mathrm{~cm}^{2}$ was put in a Petri dish ( $6.5 \mathrm{~cm}$ diameter) having $25 \mathrm{ml}$ of simulated saliva, maintained at $37^{\circ} \mathrm{C}$, with agitation at every $10 \mathrm{~s}$. The DT was recorded when the film starts to break or disintegrate [21].

Preparation of optimized orodispersible film containing naratriptan hydrochloride

After analyzing the observations of 8 batches in DoE (Table 1); finally, we got the optimized concentration of polymer and plasticizer for the final formulation in which we had incorporated naratriptan hydrochloride. Accurately weigh $10 \mathrm{mg}$ of drug and placed into the beaker containing $10 \mathrm{~mL}$ of water. Then, the solution was subjected to magnetic stirrer for dissolving the drug completely followed by addition of remaining additives. Further, the procedure was same as discussed above for the preparation of orodispersible placebo film.

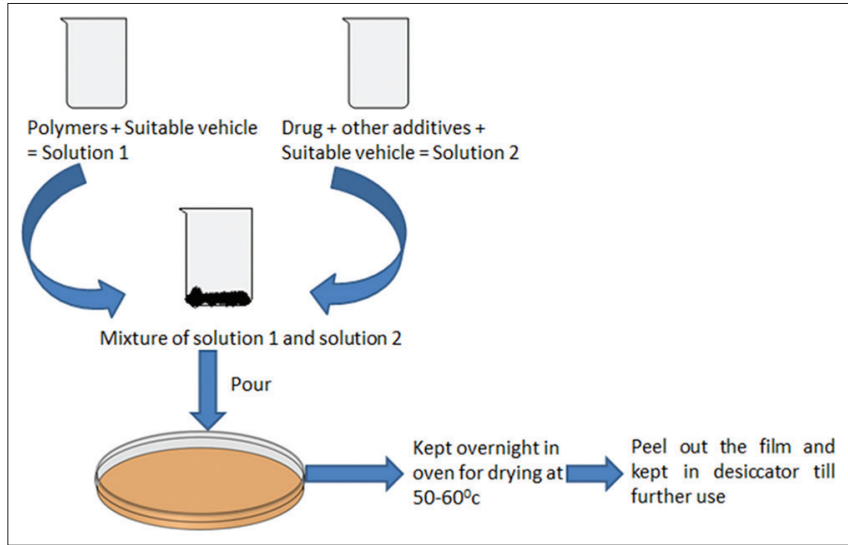

Fig. 1: Solvent casting method

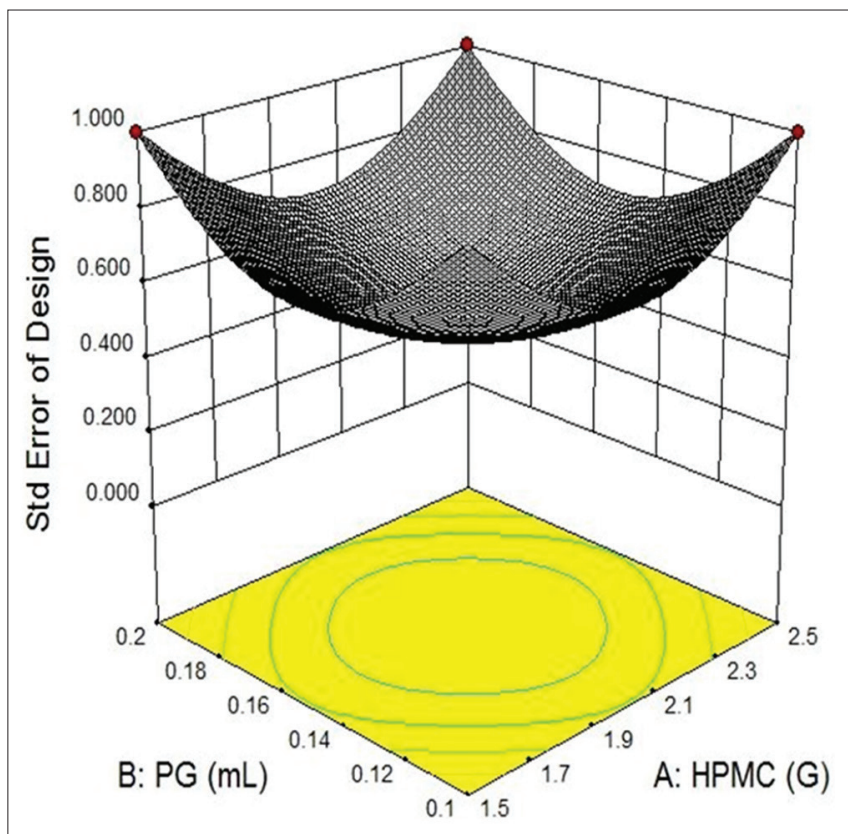

Fig. 2: Contour plot (optimization concentrations of hydroxypropyl methylcellulose $\mathrm{E} 5[2 \% \mathrm{w} / \mathrm{v}]$ and propylene glycol $(0.15 \mathrm{~mL})]$

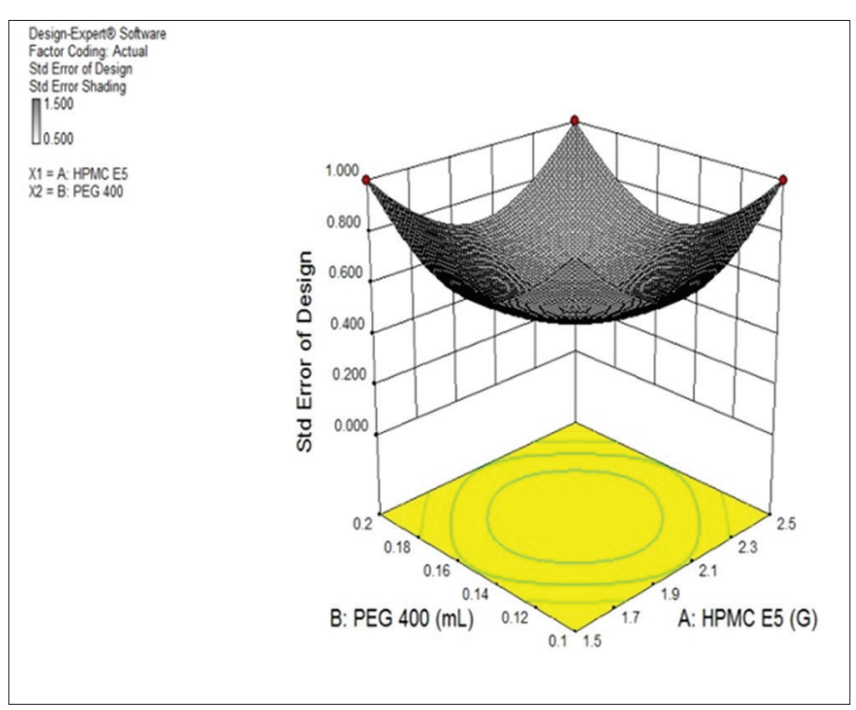

Fig. 3: Contour plot (optimization concentrations of hydroxypropyl methylcellulose E5 $[2 \% \mathrm{w} / \mathrm{v}]$ and polyethylene glycol 400 [0.15 $\mathrm{mL}]$ ) 
Evaluation of optimized formulation (Table 2)

$F D$ and in vitro $D T$

The folding endurance (FD) and in vitro disintegration time (DT) studies were performed as per the procedures mentioned under the title - Evaluation of orodispersible placebo film.

Table 1: Composition for preparation of placebo film

\begin{tabular}{llll}
\hline $\begin{array}{l}\text { Formulation } \\
\downarrow\end{array}$ & $\begin{array}{l}\text { HPMC } \\
\text { E5 }(\% \mathrm{w} / \mathrm{v})\end{array}$ & $\begin{array}{l}\text { Propylene } \\
\text { glycol }(\mathrm{mL})\end{array}$ & $\begin{array}{l}\text { PEG } \\
\mathbf{4 0 0}(\mathbf{m L})\end{array}$ \\
$\rightarrow$ & & & \\
Component & & & \\
\hline F1 & 1.5 & 0.1 & - \\
F2 & 1.5 & 0.2 & - \\
F3 & 2.5 & 0.1 & - \\
F4 & 2.5 & 0.2 & - \\
F5 & 1.5 & - & 0.2 \\
F6 & 2.5 & - & 0.1 \\
F7 & 2.5 & - & 0.2 \\
F8 & 1.5 & - & 0.1 \\
\hline
\end{tabular}

HPMC: Hydroxypropyl methylcellulose, PEG 400: Polyethylene glycol 400

Table 2: Results of prepared placebo films $(n=3)$

\begin{tabular}{lll}
\hline Formulation & DT (s) (mean \pm SD) & FD (No.) (mean \pm SD) \\
\hline F1 & $40 \pm 2$ & $135 \pm 5$ \\
F2 & $42 \pm 1$ & $164 \pm 4$ \\
F3 & $50 \pm 3$ & $223 \pm 1$ \\
F4 & $55 \pm 1$ & $112 \pm 3$ \\
F5 & $50 \pm 2$ & $192 \pm 4$ \\
F6 & $70 \pm 1$ & $191 \pm 5$ \\
F7 & $57 \pm 1$ & $350 \pm 2$ \\
\hline
\end{tabular}

F8 formulation was too sticky that is why not being peeled out. SD: Standard deviation, FD: Folding endurance

Table 3: Comparison between predicted and observed value of optimized formulation of HPMC E5 and Propylene glycol $(n=3)$

\begin{tabular}{lll}
\hline Responses & Predicted value & Observed value (mean \pm SD) \\
\hline DT (s) & 46.75 & $49 \pm 1.5$ \\
FD (no.) & 158.5 & $164 \pm 2$ \\
\hline
\end{tabular}

HPMC: Hydroxypropyl methylcellulose, SD: Standard deviation, FD: Folding endurance

Table 4: Comparison between predicted and observed value of optimized formulation of HPMC E5 and PEG $400(n=3)$

\begin{tabular}{lll}
\hline Responses & Predicted value & Observed value (mean \pm SD) \\
\hline DT (s) & 58 & $55 \pm 4$ \\
FD (no.) & 222 & $218 \pm 6$ \\
\hline
\end{tabular}

PEG 400: Polyethylene glycol 400, HPMC: Hydroxypropyl methylcellulose,

SD: Standard deviation, FD: Folding endurance

\section{In vitro drug release}

The in vitro drug release was carried out in $250 \mathrm{ml}$ of simulated saliva as dissolution medium using USP dissolution apparatus I, maintained at $37 \pm 0.5^{\circ} \mathrm{C}$ with $100 \mathrm{rpm}$. $10 \mathrm{ml}$ samples were taken at different predetermined time intervals, and the same amount of fresh dissolution medium maintained at same temperature was added to maintain the sink condition in the dissolution vessel. Samples were passed through $0.45 \mu \mathrm{m}$ membrane filter after suitable dilutions, if required and then analyzed spectrophotometrically. It was conducted 3 times for each film formulation, and the average value was taken [22]

\section{RESULTS}

The resultant formulation was transparent with a smooth texture. The outcomes of the resultant formulation are being tabulated below:

Optimized Formulation I contains the drug, hydroxypropyl methylcellulose (HPMC) E5 and propylene glycol, optimized Formulation II contains the drug, HPMC E5, and polyethylene glycol 400

\section{CONCLUSION AND DISCUSSION}

From the literature review, we came to know that using the concentration of polymer between $1.5 \% \mathrm{w} / \mathrm{v}$ and $2.5 \% \mathrm{w} / \mathrm{v}$ and plasticizer $0.1-$ $0.2 \mathrm{~mL}$, we will get the required FD, i.e. $>150$ folds and DT $<1 \mathrm{~min}$. We used same concentration of polymer and plasticizer, after that applied QbD. After applying QbD, we got an optimized formulations which show the required outcomes, i.e. FD $>150$ folds and DT $<1 \mathrm{~min}$ (Table 3 and 4). We had done the in vitro dissolution study of both optimized batches, and from the results (Table 5 and 6), it had been concluded the percentage drug release of naratriptan hydrochloride in the optimized Formulation I after 15 min was $>80 \%$ (Fig. 4). Hence, from this, we selected Formulation I for further study. From this, we concluded that QbD is very much useful approach to get an optimized formulation.

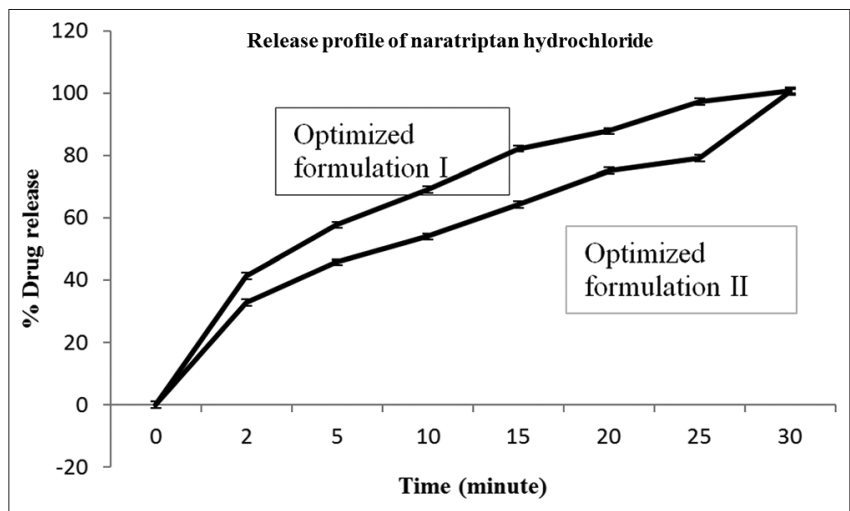

Fig. 4: In vitro drug release comparison between optimized Formulation I and optimized Formulation II.

Table 5: In vitro drug release of the film of HPMC E5 and propylene glycol $(n=3)$

\begin{tabular}{|c|c|c|c|c|c|}
\hline Time (min) & $\begin{array}{l}\text { Absorbance } \\
(\text { mean } \pm S D)\end{array}$ & $\begin{array}{l}\text { Conc. }(\mu \mathrm{g} / \mathrm{mL}) \\
(\text { mean } \pm S D)\end{array}$ & $\begin{array}{l}\text { Corrected conc } \\
(\mu \mathrm{g} / \mathrm{mL})(\text { mean } \pm S D)\end{array}$ & $\begin{array}{l}\text { Amount of drug (mg) } \\
(\text { mean } \pm \text { SD) }\end{array}$ & $\begin{array}{l}\% \text { drug release } \\
(\text { mean } \pm S D)\end{array}$ \\
\hline 0 & 0 & 0 & 0 & 0 & 0 \\
\hline 2 & $0.101 \pm 0.002$ & $0.4803 \pm 0.020$ & $0.4803 \pm 0.020$ & $0.1200 \pm 0.005$ & $41.29 \pm 1.730$ \\
\hline 5 & $0.119 \pm 0.003$ & $0.6619 \pm 0.030$ & $0.6715 \pm 0.030$ & $0.1676 \pm 0.007$ & $57.75 \pm 2.650$ \\
\hline 10 & $0.131 \pm 0.001$ & $0.7830 \pm 0.010$ & $0.8024 \pm 0.004$ & $0.200 \pm 0.001$ & $69.01 \pm 0.340$ \\
\hline 15 & $0.145 \pm 0.001$ & $0.9243 \pm 0.010$ & $0.9549 \pm 0.006$ & $0.238 \mathrm{v} 0.002$ & $82.13 \pm 0.260$ \\
\hline 20 & $0.149 \pm 0.002$ & $0.9646 \pm 0.020$ & $1.021 \pm 0.020$ & $0.2552 \pm 0.005$ & $87.81 \pm 1.840$ \\
\hline 30 & $0.160 \pm 0.001$ & $1.0756 \pm 0.010$ & $1.1723 \pm 0.010$ & $0.2929 \pm 0.002$ & $100.82 \pm 1.050$ \\
\hline
\end{tabular}

SD: Standard deviation, HPMC: Hydroxypropyl methylcellulose 
Table 6: In vitro drug release of the film of HPMC E5 and PEG $400(n=3)$

\begin{tabular}{|c|c|c|c|c|c|}
\hline Time (min) & $\begin{array}{l}\text { Absorbance } \\
(\text { mean } \pm S D)\end{array}$ & $\begin{array}{l}\text { Conc. }(\mu \mathrm{g} / \mathrm{mL}) \\
(\text { mean } \pm \text { S.D. })\end{array}$ & $\begin{array}{l}\text { Corrected conc }(\mu \mathrm{g} / \mathrm{mL}) \\
(\text { mean } \pm S D)\end{array}$ & $\begin{array}{l}\text { Amount of drug (mg) } \\
(\text { mean } \pm \text { SD) }\end{array}$ & $\begin{array}{l}\text { \% drug release } \\
(\text { mean } \pm \mathrm{SD})\end{array}$ \\
\hline 0 & 0 & 0 & 0 & 0 & 0 \\
\hline 2 & $0.095 \pm 0.003$ & $0.4195 \pm 0.030$ & $0.4195 \pm 0.030$ & $0.1048 \pm 0.007$ & $32.74 \pm 2.380$ \\
\hline 5 & $0.110 \pm 0.002$ & $0.5778 \pm 0.020$ & $0.5861 \pm 0.021$ & $0.1465 \pm 0.005$ & $45.74 \pm 1.716$ \\
\hline 10 & $0.120 \pm 0.001$ & $0.6720 \pm 0.010$ & $0.6919 \pm 0.011$ & $0.1729 \pm 0.002$ & $53.99 \pm 0.871$ \\
\hline 15 & $0.132 \pm 0.002$ & $0.7931 \pm 0.020$ & $0.8479 \pm 0.021$ & $0.2065 \pm 0.005$ & $64.26 \pm 2.026$ \\
\hline 20 & $0.144 \pm 0.003$ & $0.9142 \pm 0.030$ & $0.9634 \pm 0.031$ & $0.2408 \pm 0.008$ & $75.18 \pm 2.499$ \\
\hline 30 & $0.172 \pm 0.001$ & $1.196 \pm 0.010$ & $1.2851 \pm 0.012$ & $0.3213 \pm 0.003$ & $100.32 \pm 1.018$ \\
\hline
\end{tabular}

SD: Standard deviation, HPMC: Hydroxypropyl methylcellulose, PEG 400: Polyethylene glycol 400

\section{REFERENCES}

1. Steiner D, Finke JH, Kwade A. Redispersion of nanoparticle-loaded orodispersible films: Preservation of particle fineness. Chem Ing Tech 2017;89:1034-40.

2. Parmar D, Patel U, Bhimani B, Tripathi A, Daslaniya D, Patel G. Orally fast dissolving films as dominant dosage form for quick release. Int $\mathbf{J}$ Pharm Res BioSci 2012;1:27-41.

3. Visser JC, Woerdenbag HJ, Crediet S, Gerrits E, Lesschen MA, Hinrichs WL, et al. Orodispersible films in individualized pharmacotherapy: The development of a formulation for pharmacy preparations. Int J Pharm 2015;478:155-63.

4. Borges AF, Silva C, Coelho JF, Simões S. Oral films: Current status and future perspectives: I - Galenical development and quality attributes. J Control Release 2015;206:1-19.

5. Priyanka P, Rikisha L, Mayur C, Ujjaval S. Development and optimization of fast dissolving or dispersible film of baclofen using 32 central composite designs. Int J Pharm Sci Res 2014;5:5539-47.

6. Arya A, Chandra A, Sharma V, Pathak K. Fast dissolving oral films: An innovative drug delivery system and dosage form. Int J Chem Technol Res 2010;2:576-83.

7. Mahaparale MA, Shivnikar SS, Pawar KV, Prashant N. Fast dissolving oral films: An innovative drug delivery system. Int J Res Rev Pharm Appl Sci 2012;2:482-96.

8. Sangshetti JN, Deshpande M, Zaheer Z, Shinde DB, Arote R. Quality by design approach: Regulatory need. Arabian J Chem 2017;10:3412-25.

9. Vecchia D, Pietrobon D. Migraine: A disorder of brain excitatoryinhibitory balance? Trends Neurosci 2012;35:507-20.

10. Goadsby PJ. Migraine: Diagnosis and management. Int Med J 2003;33:436-42.

11. Skaer TL. Clinical presentation and treatment of migraine. Clin Ther 1996;18:229-45
12. Tepper SJ, Spears RC. Acute treatment of migraine. Neurol Clin 2009;27:417-27.

13. Estemalik E, Tepper S. Preventive treatment in migraine and the new US guidelines. Neuropsychiatr Dis Treat 2013;9:709-20.

14. Dhillon KS, Singh J, Lyall JS. A new horizon into the pathobiology, etiology and treatment of migraine. Med Hypotheses 2011;77:147-51.

15. Antonaci F, Natascia G, Shizheng W, Ennio P, Alfredo C. Recent advances in migraine therapy. Springerplus 2016;5:637.

16. Tayel SA, El Nabarawi MA, Amin MM, Abou Ghaly MH. Sumatriptan succinate sublingual fast dissolving thin films: Formulation and in vitro/in vivo evaluation. Pharm Dev Technol 2016;21:328-37.

17. Longmore J, Shaw D, Smith D, Hopkins R, McAllister G, Pickard JD, et al. Differential distribution of 5-HT1D and 5-HT1Bimmunoreactivity within the human trigemino-cerebrovascular system: Implications for the discovery of new antimigraine drugs. Cephalalgia 1997; 17:833-42.

18. Reuter U, Chiarugi A, Bolay H, Moskowitz MA. Nuclear factor-kappaB as a molecular target for migraine therapy. Ann Neurol 2003;51:507-16.

19. Chonkar AD, Rao JV, Managuli RS, Mutalik S, Dengale S, Jain P, et al. Development of fast dissolving oral films containing lercanidipine $\mathrm{HCl}$ nanoparticles in semi crystalline polymeric matrix for enhanced dissolution and ex vivo permeation. Eur $\mathrm{J}$ Pharm Biopharm 2016;103:179-91.

20. Sharma R, Kamboj S, Singh G, Rana V. Development of aprepitant loaded orally disintegrating films for enhanced pharmacokinetic performance. Eur J Pharm Sci 2016;84:55-69.

21. Mishra R, Amin A. Formulation and characterization of rapidly dissolving films of cetirizine hydrochloride using pullulan as a film forming agent. Indian J Pharm Educ Res 2011;45:71-7.

22. Saxena PR, De Vries P, Villalón CM. 5-HT1-like receptors: A time to bid goodbye. Trends Pharmacol Sci 1998;19:311-6. 